\title{
PRIORIZAÇÃO DE ESTRATÉGIAS PARA GERENCIAMENTO DE RESÍDUOS SÓLIDOS DA CONSTRUÇÃO CIVIL
}

\author{
Adalberon da Silva (UNINASSAU CARUARU) adalberonb@gmail.com \\ Anna Beatriz Galindo (UNINASSAU CARUARU) anna_beatriz26@ hotmail.com \\ Marina Lima (UNINASSAU CARUARU) marina.eng2018@gmail.com \\ Ramivaldo Silva (UNINASSAU CARUARU) ramivaldo@gmail.com \\ Wesley Silva (UFPE) wesleydosilva@gmail.com
}

\section{Resumo}

As pequenas e médias empresas são responsáveis pela geração de um considerável montante de resíduos sólidos, estando também inseridas nesse contexto as que têm sua produção voltada para a construção civil. Todavia, por falta de informação, muitas vezes, essas empresas acabam negligenciando a gestão adequada de resíduos em seus processos, o que acarreta problemas para toda sociedade. Nesse sentido, este trabalho teve como finalidade realizar um estudo para priorização de estratégias acerca da gestão de resíduos sólidos em pequenas e médias empresas da construção civil. Para que isso fosse possível um estudo de caso foi apresentado, onde se utilizaram as matrizes GUT e BASICO visando elencar e priorizar os principais problemas e estratégias da organização no gerenciamento de resíduos. Os resultados mostraram que as estratégias identificadas e priorizadas, que foram a metodologia $5 \mathrm{~s}$ e logística reversa, trouxeram benefícios de ordem econômica, social e ambiental, além de uma imagem valorada da empresa no mercado.

Palavras-Chave: Gerenciamento de Resíduos Sólidos; Matriz GUT e BASICO; Priorização de Estratégias; Logística Reversa; Programa 5S.

\section{Introdução}

A evolução tecnológica decorrente do processo de globalização alterou a forma como os indivíduos se relacionam entre si e com o meio ao qual estão inseridos. Como resultado dessa evolução se destaca o rápido crescimento da geração de resíduos em indústrias de todos os ramos, inclusive o da construção civil (KINOBE et al.,2015).

Sob essa perspectiva, Oteng-Ababio et al. (2013) afirmam que autoridades de todo o mundo estão empenhadas na diminuição da geração de resíduos, de modo que a recuperação desses resíduos possa trazer benefícios de classe econômica, ambiental e social.

A logística reversa (LR) tem sido uma alternativa explorada na correta destinação de resíduos (PRAHINSKI \& KOCABASOGLU, 2006). Todavia, muitas organizações podem não deter conhecimento suficiente para gerir a logística reversa corretamente (FONTANA \& 
HOLANDA, 2019), o que parece ser o caso de empresas de menor porte da construção civil, resultando em um incorreto descarte dos resíduos gerados por essas empresas.

Dessa forma, o presente estudo teve como objetivo associar as ferramentas GUT e BASICO para identificar e priorizar estratégias para o gerenciamento adequado de resíduos sólidos em pequenas e médias empresas (PMEs) da construção civil. A utilização dessas ferramentas concede condições adequadas para analisar problemas específicos, oferecendo uma ajuda metodológica para realizar um plano de ação de forma simples (FERROLI et al, 2000).

Assim, é plausível a utilização dessas ferramentas para auxiliar o gerenciamento de resíduos sólidos nas PMEs da construção civil, visto que, muitas vezes, essas empresas podem não dispor de conhecimento rebuscado para utilização de ferramentas mais complexas (MENDES et al., 2019).

Não obstante, os estudos acerca da utilização das matrizes GUT e BASICO para o contexto do gerenciamento de resíduos sólidos parecem não ter avançado, pois não foram identificados trabalhos nesse sentido, isso reitera o caráter inovador dessa pesquisa e sua contribuição para a área.

Este artigo está organizado em secções, sendo a primeira secção de caráter introdutório. A secção 2 apresenta o referencial teórico e metodológico de conceitos importantes que basearam ou foram resultado desse estudo. Na secção 3 são descritos os materiais e métodos utilizados. A secção 4 descreve um estudo de caso real. As secções 5 e 6 apresentam resultados e discussões e conclusões, respectivamente.

\section{Referencial teórico e metodológico}

Nesta secção é discutido o referencial teórico e metodológico usado para o andamento do estudo aqui apresentado.

\subsection{Logística reversa}

Nos últimos anos é notável o crescimento da industrialização e do desempenho econômico, essas questões acarretam algumas consequências, principalmente ambientais, que podem ser consideradas irreparáveis, ou talvez, com um tempo de reparação muito elevado. Com vistas a incentivar o progresso, proporcionando a inserção de questões econômicas, ambientais e sociais, a LR é vista por alguns como uma definição organizacional promitente, que atende a essas questões (de BRITO \& de KOSTER, 2004; ÁLVAREZ-GIL et al., 2007; CARTER \& ROGERS, 2008; HUANG \& YANG, 2014). 
Nesse contexto, a LR tem particularidades que a diferenciam da logística do fluxo direto. As principais delas, para Guide \& VanWassenhove (2002), são: a imprecisão em relação ao tempo, a quantidade e qualidade dos produtos que retornam, tornando a gestão no fluxo reverso mais desafiadora.

Em geral, para ser realizada a LR conta com algumas operações: Aquisição, manuseio, coleta, inspeção e triagem e disposição final. A aquisição diz respeito ao ponto de partida para uma LR rentável através dos produtos usados, componentes ou materiais dos usuários finais para processamentos adicionais (GUIDE et al., 2003; AGRAWAL et al., 2015). O manuseio consiste, principalmente, em armazenagem provisória, transporte interno e inspeção inicial dos bens retornados (de BRITO \& de KOSTER, 2004). A coleta refere-se à atividade na qual a empresa ganha a posse do produto (FLEISCHMANN et al., 2000; NUSS et al., 2015).

Após serem coletados, os bens são inspecionados e triados. A inspeção é necessária para identificar quais são os bens desejados e indesejados. Já a triagem visa distinguir quais produtos deveriam ser recuperados daqueles que a organização irá se desfazer (GALBRETH \& BLACKBURN, 2006; NUSS et al., 2015). Por conseguinte, a disposição final considera algumas opções, como: reciclagem, reuso, remanufatura, reparo e descarte, a depender dos objetivos da organização para implementação da LR e das características dos resíduos.

Nesse sentido, na visão de Kocabasoglu et al. (2007) para adotar e implementar a LR nas organizações a alta gerência tem que compreender a relevância dela para inseri-la no planejamento estratégico e investimento de recursos. Dessa forma, as Matrizes GUT e BASICO são algumas das ferramentas que podem ser utilizadas para auxiliar nessa avaliação.

\subsection{Matriz GUT}

A matriz Gravidade, Urgência e Tendência (GUT) tem sua essência baseada na exploração de problemas e sua priorização, utilizando-se de medidas subjetivas e de fácil entendimento (CESAR,2013; MENDES et al., 2019). Segundo Ferreira et al. (2014) cada letra na sigla GUT tem o seu significado em um item de avaliação, sendo eles:

- Gravidade $(\mathrm{G})$ : representa a proporção do problema para a organização;

- Urgência (U): a urgência do problema envolvendo o tempo disponível para resolvê-lo;

- Tendência (T): o potencial de crescimento do problema para organização, caso não seja realizada alguma ação eficaz. 
Assim, cada problema detectado deve ser analisado de acordo com os elementos da matriz GUT, atribuindo uma nota na escala Likert de 5 pontos, com significado de que quanto maior o valor atribuído pior é a avaliação do problema detectado naquele item da matriz GUT (MENDES et al., 2019).

Por conseguinte, é calculado um produtório com o valor atribuído a cada item dos problemas encontrados, resultando assim em um índice global. Os índices globais de cada problema são posteriormente transformados em um ranking que indicará a ordem de prioridade de resolução dos problemas. O plano de ação pode ser construído pelo uso da matriz BASICO (FERROLI et al, 2000).

\subsection{Matriz BASICO}

A matriz Benefícios, Abrangência, Satisfação, Investimentos, Clientes e Operacionalização (BASICO), trabalha de forma semelhante à matriz GUT. Contudo, difere, pois prioriza as estratégias para resolução dos problemas identificados na matriz GUT. Esse tipo de matriz também utiliza o modelo de avaliação da escala Likert de 5 pontos, segundo Mendes et al. (2019). Os itens avaliados na matriz BASICO, suas definições e o significado dos níveis da escala estão apresentados no Quadro1.

Quadro 1 - Itens avaliados pela matriz BASICO

\begin{tabular}{|c|c|c|}
\hline Item Avaliado & Definição & Escala Likert \\
\hline Benefícios (B) & $\begin{array}{l}\text { Beneficios advindos } \text { da } \\
\text { solução avaliados para } \\
\text { organização }\end{array}$ & 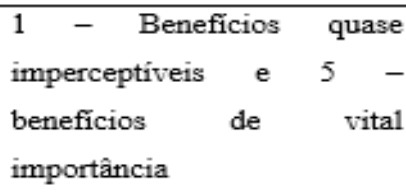 \\
\hline Abrangência (A) & $\begin{array}{l}\mathrm{O} \text { impacto sentido por } \\
\text { clientes internos e externos }\end{array}$ & $\begin{array}{l}1-\text { Abrangência muito } \\
\text { pequena e } 5 \text { - abrangência } \\
\text { muito grande }\end{array}$ \\
\hline Satisfação (S) & $\begin{array}{l}\text { A satisfação alcançada com } \\
\text { a solução }\end{array}$ & $\begin{array}{l}1 \text { - Quase não é notada e } 5 \text { - } \\
\text { satisfação muito grande }\end{array}$ \\
\hline Investimento (I) & $\begin{array}{l}\text { Investimento essencial para } \\
\text { obter a estratégia }\end{array}$ & $\begin{array}{l}\text { 1-Altissimos investimentos } \\
\text { e } 5-\text { pouquíssimos } \\
\text { investimentos }\end{array}$ \\
\hline Cliente (C) & $\begin{array}{l}\text { A maneira como os clientes } \\
\text { serão afetados com as } \\
\text { soluções }\end{array}$ & $\begin{array}{l}1 \text { - Impacto muito grande e } 5 \\
\text { - nenhum impacto }\end{array}$ \\
\hline Operacionalização (O) & $\begin{array}{lr}\text { Os impasses } & \text { para } \\
\text { operacionalizar com as } \\
\text { soluções }\end{array}$ & $\begin{array}{l}1 \text { - Muito dificil e } 5 \text { - muito } \\
\text { fácil }\end{array}$ \\
\hline
\end{tabular}

Fonte: Os Autores (2019) 
O processo de obtenção do índice global é o mesmo da matriz GUT. E as estratégias principais são priorizadas. Os materiais e métodos desse estudo são apresentados subsequentemente.

\section{Materiais e métodos}

No estudo apresentado, cinco etapas foram seguidas conforme pode ser visto na Figura 1.

Figura 1 - Etapas da Pesquisa

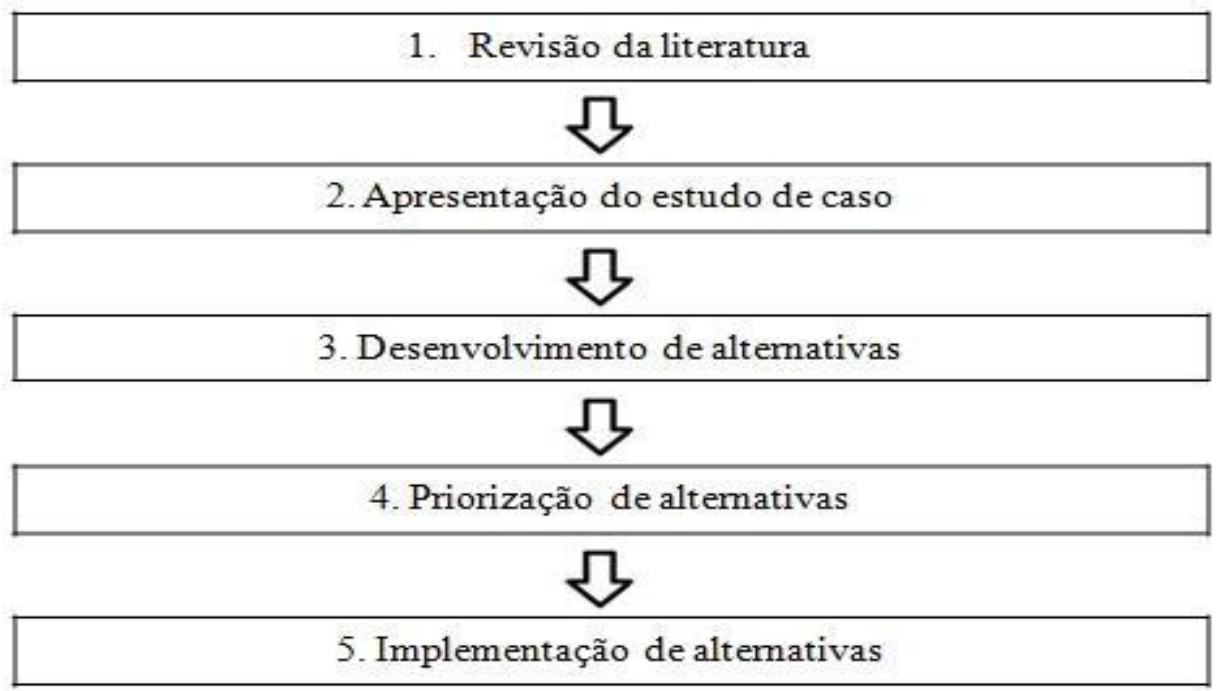

Fonte: Os Autores (2019)

- $1^{a}$ Etapa - Revisão da literatura: nessa etapa foi realizada uma revisão da literatura sobre os principais temas que basearam esse estudo, sendo os resultados apresentados na forma do referencial teórico e pesquisas relevantes;

- $2^{\text {a }}$ Etapa - Apresentação do estudo de caso: buscaram-se empresas que permitissem a consecução dessa pesquisa, apresentando, informando e explorando dados relevantes sobre o mesmo. Após esses, diante de uma análise, os principais problemas enfrentados na empresa objeto de estudo foram identificados e priorizados através da utilização da Matriz GUT;

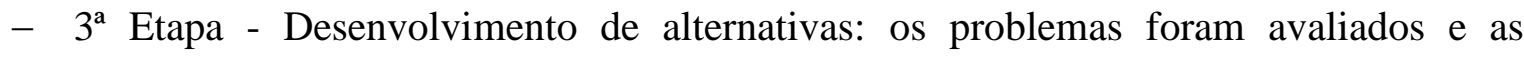
alternativas para sua resolução foram identificadas juntamente com o gestor da empresa;

- $4^{\text {a }}$ Etapa - Priorização das alternativas: nessa, a Matriz BASICO foi utilizada para priorizar as alternativas necessárias para solucionar os problemas enfrentados;

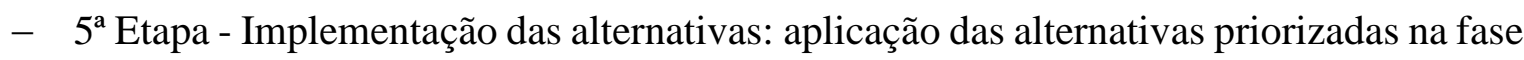
anterior para que seu impacto fosse avaliado. 
Por conseguinte, o estudo de caso é apresentado.

\section{Estudo de caso}

O presente estudo foi realizado na empresa "Portas Dura Mais", nome arbitrado de forma fictícia visando resguardar as informações da empresa objeto de estudo que se situa no município de Belo Jardim - PE, à 173 Km da capital Recife.

No período em que se deu o supracitado estudo, de junho a agosto de 2019, a empresa contava com o total de 225 colaboradores, sendo, de acordo com o SEBRAE (2013), caracterizada como uma empresa de médio porte. Os referidos colaboradores se encontravam alocados nos departamentos de produção, logística, vendas, jurídico, compras e recursos humanos.

No setor de produção eram produzidas as portas e kits portas prontas; a logística era responsável pelo estoque e distribuição dos produtos acabados até o cliente final; o setor de vendas, por sua vez, era o mais próximo do consumidor final, sendo responsável pela realização das vendas, apresentação de novos produtos, além de prestar atendimentos relacionados à assistência técnica.

Ao setor jurídico pertencia às responsabilidades contratuais como emissão de notas fiscais, pagamentos de impostos e assessoria contábil; o setor de compras possuía responsabilidades sobre a aquisição de matéria prima, contato, seleção e classificação de fornecedores. Por fim o setor de recursos humanos possuía funções como, por exemplo, a gestão de pessoas, contrato e treinamento de colaboradores.

\subsection{Processo produtivo}

A empresa Portas Dura Mais produz portas de madeira. Por ser uma empresa de médio porte tem o seu processo produtivo sistematicamente simples e pode ser sintetizado pelas máquinas em que o material é processado na seguinte ordem:

- Prensa de alta pressão: nesse equipamento é feita a união de componentes ( 2 folhas de MDF, 2 bases, 1 preenchimento e cola branca);

- Seccionadora: nesse equipamento é feita a remoção dos excessos do topo e da base, a fim de que se obtenha o produto acabado com tamanho padronizado;

- Estufa de pintura: nesse equipamento as laterais das portas são pintadas com as mesmas cores de suas faces;

- Plastificadora: nesse equipamento o produto acabado é envolvido em uma película plástica para que esse seja perfeitamente alocado no estoque; 
- Estoque: local de armazenagem do produto acabado que está aguardando o procedimento de expedição.

\section{Resultados e discussões}

Após essa etapa de análise dos processos e coleta das informações necessárias acerca do funcionamento da empresa, o seu gestor foi contactado para que os principais problemas da organização fossem elicitados. Esses problemas e suas descrições estão elencadas no Quadro 2.

Quadro 2 - Problemas definidos pelo gestor

\begin{tabular}{|c|l|}
\hline Problema & Descricão \\
\hline 1. Desperdício de Matéria- & $\begin{array}{l}\text { Foi identificado que muita matéria-prima estava sendo } \\
\text { desperdiçada na etapa de acabamento das portas, } \\
\text { phegando a quase } 3 \text { toneladas de material no periodo de } \\
\text { julho a agosto de 2019. }\end{array}$ \\
\hline 2. Retrabalho no processo & $\begin{array}{l}\text { Máquina plastificadora desregulada por falta de } \\
\text { manutenção preventiva, causada pela falta de } \\
\text { organização no planejamento. }\end{array}$ \\
\hline 3. Devoluções de portas & $\begin{array}{l}\text { As portas estavam sendo devolvidas devido a danos } \\
\text { ocasionados durante o processo logístico, que é } \\
\text { terceirizado. }\end{array}$ \\
\hline 4. Atrasos no processo & $\begin{array}{l}\text { Esses atrasos eram ocasionados devido a desorganização } \\
\text { do ambiente fabril e a falta de treinamento de muitos } \\
\text { colaboradores recentemente contratados. }\end{array}$ \\
\hline
\end{tabular}

Fonte: Os Autores (2019)

Após a identificação dos problemas foi efetuada a sua classificação de prioridade de resolução a partir da matriz GUT. A responsabilidade de atribuição das notas de cada item avaliado (Gravidade, Urgência e Tendência) ficou incumbida ao gestor da organização, cujo resultado está expresso na Tabela 1. 


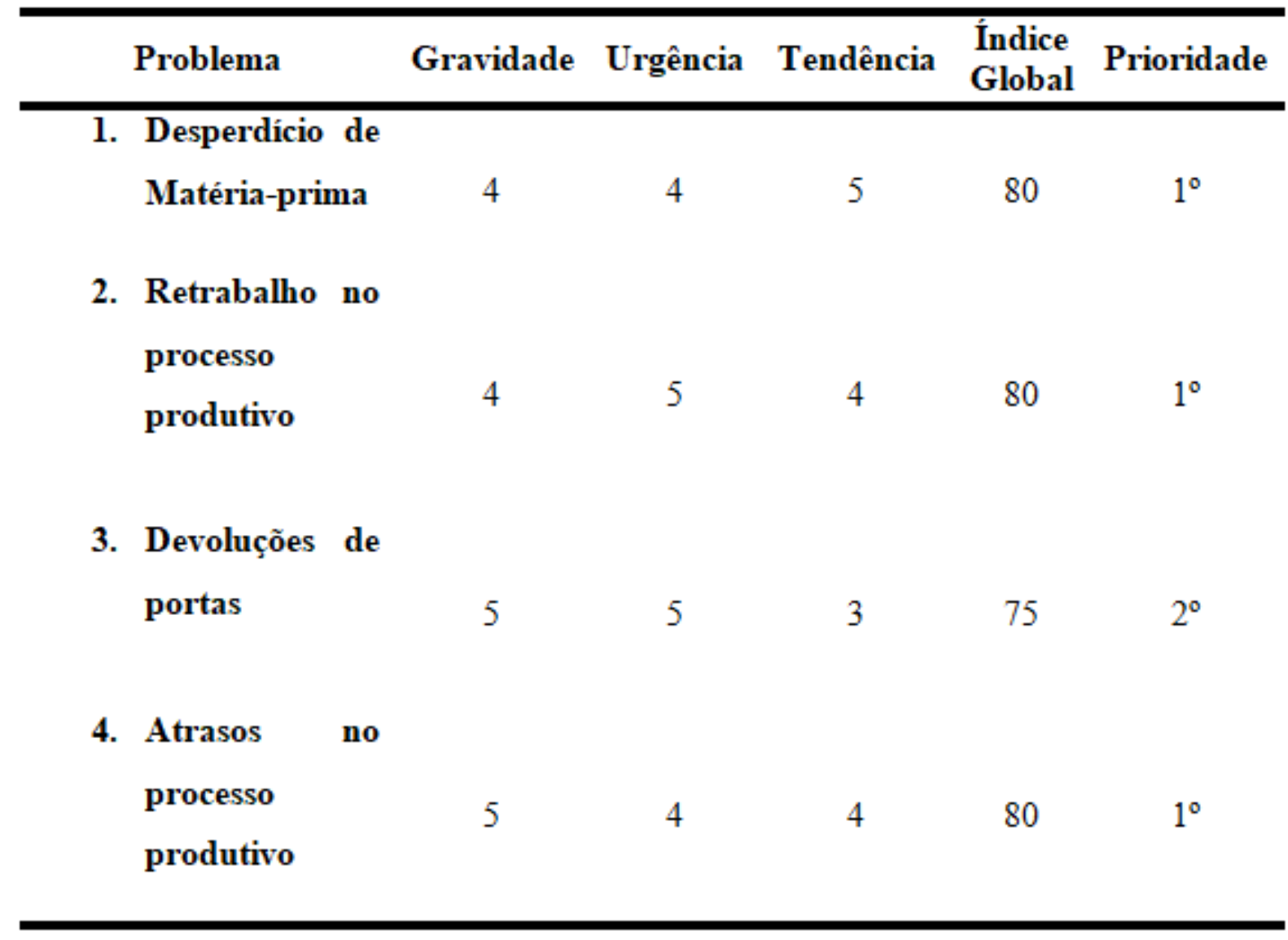

Fonte: Os Autores (2019)

\subsection{Desenvolvimento e priorização de alternativas}

Subsequentemente, dada a existência dos problemas já priorizados, esses passaram por criteriosa avaliação do gestor para que fossem geradas alternativas estratégicas para a resolução desses problemas. Assim, o gestor chegou às alternativas que estão dispostas no Quadro 3. 
Quadro 3 - Alternativas desenvolvidas

\begin{tabular}{|l|l|}
\hline Alternativa & Descrição \\
\hline $\begin{array}{l}\text { 1. Utilização da } \\
\text { logística reversa }\end{array}$ & $\begin{array}{l}\text { Identificar um potencial comprador dos resíduos gerados advindo } \\
\text { da matéria-prima utilizada durante o processo produtivo, com o } \\
\text { intuito de gerar renda extra para a organização. }\end{array}$ \\
\hline $\begin{array}{l}\text { 2. Compra } \\
\text { caminhão próprio }\end{array}$ & $\begin{array}{l}\text { Comprar caminhão próprio ao invés de terceirizar o processo } \\
\text { logístico, diminuindo, assim, as devoluções ocasionadas pelos } \\
\text { danos durante a entrega dos pedidos aos clientes. }\end{array}$ \\
\hline $\begin{array}{l}\text { 3. Aplicação dos 5S } \\
\text { 4. Certificação }\end{array}$ & $\begin{array}{l}\text { Utilização dos 5 sensos para organizar o ambiente fabri1, } \\
\text { impactando positivamente o processo produtivo e saúde dos } \\
\text { trabalhadores. }\end{array}$ \\
\hline $\begin{array}{l}\text { ISO 9000 } \\
\text { manutenção }\end{array}$ & $\begin{array}{l}\text { Realizar a certificação da ISO 9000 por órgão regulador para } \\
\text { garantir a gestão da qualidade adequada em todos os processos da } \\
\text { empresa. }\end{array}$ \\
\hline $\begin{array}{l}\text { fabril } \\
\text { máquinas novas }\end{array}$ & $\begin{array}{l}\text { Treinamento de World Class Manufacturing para os colaboradores } \\
\text { da empresa, com o intuito de desenvolvimento de plano de } \\
\text { manutenção preventiva na organização. }\end{array}$ \\
\hline $\begin{array}{l}\text { Expandir a planta fabril por compra de terreno ao lado da fábrica } \\
\text { para minimizar o retrabalho no processo produtivo. } \\
\text { problemas relacionados à falta de organização da fábrica. }\end{array}$ \\
\hline
\end{tabular}

Fonte: Os Autores (2019)

A priorização de alternativas deu-se com a utilização da matriz BASICO, onde cada dimensão dessa matriz foi avaliada pelo gestor da organização. A avaliação chegou aos resultados expressos na Tabela 2. 
Tabela 2 - Priorização de alternativas

\begin{tabular}{|c|c|c|c|c|c|c|c|c|}
\hline Alternativas & B & A & $\mathrm{S}$ & $I$ & $\mathrm{C}$ & 0 & Indice Global & Prioridade \\
\hline $\begin{array}{l}\text { 1. Utilização da Logística } \\
\text { Reversa }\end{array}$ & 5 & 4 & 5 & 3 & 1 & 4 & 1200 & $1^{\circ}$ \\
\hline $\begin{array}{l}\text { 2. Compra de Caminhão } \\
\text { Próprio }\end{array}$ & 3 & 2 & 1 & 1 & 1 & 1 & 6 & $6^{\circ}$ \\
\hline 3. Aplicação dos $5 \mathrm{~S}$ & 5 & 5 & 4 & 4 & 1 & 3 & 1200 & $1^{\circ}$ \\
\hline $\begin{array}{l}\text { 4. Certificação pela ISO } \\
9000\end{array}$ & 5 & 5 & 5 & 1 & 1 & 1 & 125 & $3^{\circ}$ \\
\hline $\begin{array}{l}\text { 5. Expansão da Planta } \\
\text { Fabril }\end{array}$ & 4 & 5 & 4 & 1 & 1 & 1 & 80 & $4^{\circ}$ \\
\hline $\begin{array}{l}\text { 6. Comprade Máquinas } \\
\text { Novas }\end{array}$ & 4 & 3 & 2 & 1 & 1 & 2 & 48 & $5^{\circ}$ \\
\hline $\begin{array}{l}\text { 7. Plano de Manutenção } \\
\text { Preventiva }\end{array}$ & 3 & 3 & 4 & 2 & 3 & 4 & 864 & $2^{\circ}$ \\
\hline
\end{tabular}

Fonte: Os Autores (2019)

Destarte, as alternativas passíveis de serem executadas, de imediato, foi a utilização da logística reversa e aplicação dos $5 \mathrm{~S}$, haja vista que ambas foram classificadas em primeiro lugar na classificação dos resultados da matriz. Essas alternativas foram implementadas. 


\subsection{Implementação das alternativas}

A implementação das alternativas se deu de modo simultâneo, logo a utilização da logística reversa e aplicação dos $5 \mathrm{~S}$ ocorreram concomitantemente. Para que fosse possível a utilização da logística reversa todo processo de produção da organização foi analisado no que se refere à geração de resíduos.

Nessa análise verificou-se que o material advindo do retrabalho da máquina plastificadora poderia servir como matéria-prima para uma determinada empresa produtora de prendedor de roupas. Este resíduo pode ser verificado na Figura 2.

Figura 2 - Material aguardando pesagem

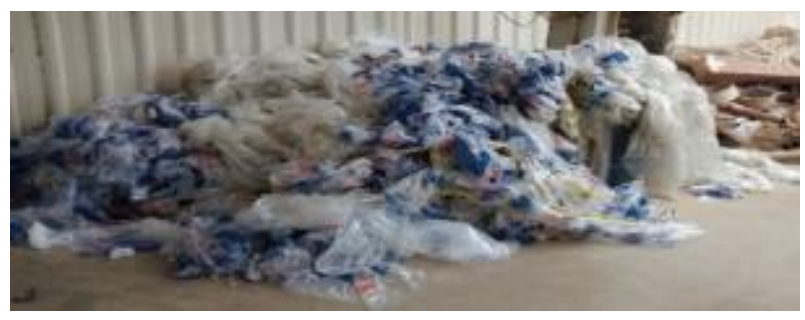

Fonte: Os Autores (2019)

Após a constatação supracitada, houve contato e negociação entre as empresas a fim de que ficasse estabelecido como se daria o processo de logística reversa e quais seriam os benefícios para ambas.

A partir disso, o material de retrabalho oriundo da máquina plastificadora foi alocado em um determinado espaço da organização e ao final de cada mês foi efetuada a pesagem e cálculo do valor que deveria ser pago pela empresa compradora. Após isso, o material era enviado para a compradora que passou a fazer uso deste material em seu processo produtivo para prendedores.

É importante frisar que os recursos advindos da venda dos resíduos foram utilizados na aplicação dos $5 \mathrm{~S}$ e em um plano de manutenção preventiva do maquinário da organização, que foram as demais alternativas priorizadas para implementação em primeiro e segundo lugar respectivamente. Ficou evidente, para a implantação dos $5 \mathrm{~S}$, que seria necessário conscientizar todos os colaboradores da organização, até a alta gestão, acerca da fundamental importância dessa metodologia.

Nesse sentido, foram desenvolvidas ações educativas com o intuito de instruir os colaboradores no que se refere a importância da metodologia 5S para a organização.

Por conseguinte, os 5S foram implementados, as suas etapas compreenderam: 
- Seiri - Senso de utilização: nessa etapa foi possível aumentar a utilização dos departamentos e linha de produção a partir da redução de materiais inutilizados desses locais. Para isso, objetos e materiais foram alocados de acordo com sua utilização, que ia desde materiais de alta frequência de utilização até materiais não utilizados e que deveriam ser adequadamente descartados. Com o uso desse senso foi possível estabelecer um ambiente laboral estruturado de acordo com as necessidades de uso de material;

- Seiton - Senso de organização: nesse senso deu-se continuidade ao que foi desenvolvido senso de utilização. Materiais que eram importantes ao processo produtivo, mas possuíam pouca frequência de utilização, foram alocados em caixas organizadoras etiquetadas para que fossem facilmente identificadas no momento de sua utilização. Com a aplicação desse senso constatou-se maior agilidade nos processos operacionais;

- Seiso - Senso de limpeza: a utilização desse senso tornou possível identificar todas as atividades que geravam sujeiras, sendo essas sujeiras combatidas desde a sua fonte a partir da conscientização dos colaboradores sobre a necessidade de manter o ambiente limpo. A aplicação desse senso proporcionou um ambiente mais salubre aos colaboradores, o que também influenciou em uma maior satisfação e produtividade no ambiente laboral;

- Seiktsu - Senso de padronização: a utilização desse senso se deu a partir da padronização dos sensos anteriores. Para que essa padronização fosse mantida, foram identificados colaboradores responsáveis por cada tarefa e sua inspeção com vistas a manter o ambiente ocasionado pela aplicação da abordagem $5 \mathrm{~S}$;

- Shitsuke - Senso de disciplina: ao chegar nesse senso já foi notória a alteração no comportamento profissional de todos os colaboradores da organização e todas as práticas idealizadas nos sensos anteriores já faziam parte de uma rotina que era naturalmente seguida por todos, tendo como principal resultado um processo de melhoria contínua na empresa.

Os impactos da aplicação da metodologia $5 \mathrm{~S}$ foram fortemente evidenciados no estoque da organização, onde as portas passaram a ser organizadas por cores e tamanhos, o que conferiu grande agilidade e praticidade ao processo. A Figura 3 expõe a nova realidade na prática. 
Figura 3 - Estoque de portas

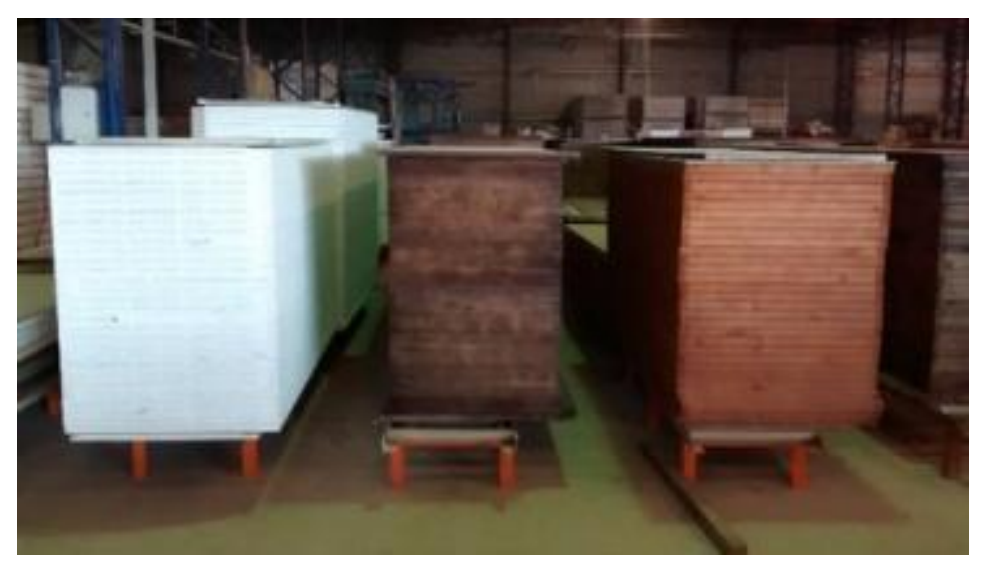

Fonte: Os Autores (2019)

De modo geral, com a aplicação da logística reversa foi possível atacar os problemas relativos ao desperdício de matéria-prima e retrabalho no processo produtivo, enquanto com a aplicação da metodologia 5S foi possível ir além desses problemas, também atacando o problema que causava atrasos no processo produtivo. É válido destacar, também, o plano de manutenção preventiva desenvolvido, que diminuiu os custos com manutenção corretiva e paradas não programadas no processo produtivo.

Desta forma, foi possível perceber o impacto das alternativas priorizadas e implementadas bem como sua abrangência na resolução de 3 dos 4 problemas principais identificados na empresa.

\section{Conclusões}

Este estudo possibilitou entender como o gerenciamento de resíduos sólidos em pequenas e médias empresas da construção civil pode ser melhorado a partir da utilização combinada de ferramentas de gestão relativamente simples, como as matrizes GUT e BASICO, que foi o objetivo pretendido. Com isso, foi possível perceber que a identificação e priorização de problemas da organização e as suas respectivas alternativas de resolução com essas matrizes se deram de modo indubitável e coerente.

Ademais, a utilização da logística reversa trouxe, para a empresa alvo do estudo, benefícios de ordem ambiental, econômica e social. Acerca dessa ideia foi possível identificar que os resíduos gerados no processo produtivo foram vendidos, sendo os lucros dessa operação direcionados a novos projetos da empresa, como a implementação da metodologia 5S.

A LR, também, pode-se associar a nova imagem da organização frente aos clientes, haja vista que as ações implementadas fizeram desta uma empresa ambientalmente correta, que gerencia 
seus resíduos de forma adequada, o que se configurou como fonte de vantagem competitiva no mercado.

Outrossim, a aplicação da metodologia 5S proporcionou uma mudança cultural na organização onde todos colaboradores foram impactados de forma positiva, conferindo um ambiente laboral mais salubre, organizado e capaz de atender as necessidades dos consumidores de forma mais eficiente, o que também gerou nos colaboradores sentimento de satisfação por fazer parte daquele ambiente produtivo.

Outra contribuição prática é sobre o fato de que todas as ferramentas e alternativas desenvolvidas nesse estudo são de fácil utilização, haja vista que são ferramentas simples e intuitivas, podendo ser aplicadas a empresas de pequeno e médio porte da construção civil que podem apresentar um nível instrucional menos formalizado. A metodologia utilizada nesse estudo também pode ser aplicada no contexto de outras organizações, visto que possui um escopo simples e adaptável acerca das ferramentas que utilizam.

Como limitação desse estudo, pode-se verificar a questão de ter sido estudada apenas uma empresa. Nesse sentido, sugere-se para trabalhos futuros a reaplicação dessa metodologia em outras empresas como forma de verificar o impacto dos seus resultados para que possam ser desenvolvidas, assim, um patamar de melhores práticas para o gerenciamento de resíduos em pequenas e médias empresas da construção civil.

\section{REFERÊNCIAS}

AGRAWAL, Saurabh; SINGH, Rajesh K. and MURTAZA, Qasim. A literature review and perspectives in reverse logistics. Resources, Conservation and Recycling, 2015, vol. 97, s.n, pp.76-92.

ÁLVARES-GIL, María; BERRONE, Pascual; HUSILLOS, F. Javier and LADO, Nora. Reverse logistics, stakeholders' influence, organizational slack, and managers' posture. Journal of Business Research. 2007 , vol. 60, n.5, pp. 463-473.

CARTER, Craig and ROGERS, Dale. A framework of sustainable supply chain management: moving toward new theory. International Journal of Physical Distribution \& Logistics Management. 2008, vol.38, n.5, pp. 360-387.

CESAR, F. I. G. Ferramentas Gerenciais da Qualidade, São Paulo: Seven System International Ltda., 2013, s.p.

DE BRITO, M.; DE KOSTER, M. Product and material returns: handling and warehousing issues. Reverse Logistics. 2004, s.v, s.n., pp. 135- 153.

AZEVEDO, Ferreira Maxwel. Quatro Ferramentas Administrativas Integradas para o Mapeamento de Falhas: Um Estudo de Caso. Revista UNIABEU. 2014, vol.7, n.16, s.p.

FERROLI, Paulo Cesar Machado. Fábricas de Subprodutos de Origem Animal: a Importância do Balanceamento das Cargas dos Digestores de Vísceras. Production, 2000, vol. 10, n.2, pp. 6-19. 
FLEISCHMANN, Moritz; KRIKKE, H.; DEKKER Rommert and FLAPPER, Simme A characterization of logistics networks for product recovery. Omega, The International Journal of Management Science. 2000, vol.8, s.n., pp. 653-666.

FONTANA, Marcele and HOLANDA, Cínthia. A multicriteria decision analysis on strategic operations in postsale reverse logistics: a case study. Produção em Foco. 2019, vol.9, n.1,pp.73-97.

GALBRETH, Michael and BLACKBURN, Joseph. Optimal acquisition and sorting policies for remanufacturing. Production and Operation Management. 2006, vol.15, n.3, pp. 384-92.

GUIDE, Daniel and VAN WASSENHOVE, Luk. The reverse supply chain: smart manufacturers are designing efficient processes for reusing their products. Harvard Business Review. 2002, vol.22, s.n., pp. 25-26.

GUIDE, Daniel; VAN WASSENHOVE, Luk and TEUNTER, Ruud. Matching demand and supply to maximize profits from remanufacturing. Manufacturing \& Service Operations Management. 2003, vol. 5, n.4, pp. 303316.

HUANG, Yi-Chun and YANG, Min-Li. Reverse logistics innovation, institutional pressures and performance. Management Research Review. 2014, vol.37, n.7, pp. 615-641.

KINOBE, Joel; GEBRESENBET, Girma; NIWAGABA, Charles and VINNERAS, Björn Reverse logistics system and recycling potential at a landfill : A case study from Kampala City. Waste Management. 2015, vol.42, s.n., pp. 82-92.

KOCABASOGLU, Canan; PRAHINSKI, Carol and KLASSEN, Robert. Linking forward and reverse supply chain investments: The role of business uncertainty. Journal of Operations Management. 2007, vol.25, n.6, pp. 1141-1160.

MENDES, Juliana Veiga; OLIVEIRA, G.R and DE SOUZA CAMPOS, M. The G-Index: a sustainability reporting assessment tool. International Journal of Sustainable Development \& World Ecology. 2019, vol.26, n.5, s.p.

NUSS, Christian; SAHAMIE, Ramin and STINDT, Dennis. The Reverse Supply Chain Planning Matrix: A Classification Scheme for Planning Problems in Reverse Logistics. International Journal of Management Reviews. 2015, vol. 17, n.4, pp. 413-436.

OTENG-ABABIO, Martin; ARGUELLO, Jose and GABBAY, Offira. Solid waste management in African cities: sorting the facts from the fads in Accra. Habitat International. 2013, vol.39, s.n., pp.96-104.

PRAHINSKI, Carol and KOCABASOGLU, Canan. Empirical research opportunities in reverse supply chains. Omega. 2006, vol.34, n.6, pp. 519-532.

SEBRAE. Definição de porte de estabelecimentos segundo o número de empregados, 2013. Disponível em: <https://m.sebrae.com.br/Sebrae/Portal\%20Sebrae/UFs/SP/Pesquisas/MPE_conceito_empregados.pdf > Acesso em: 22 out. 2019. 